\title{
Integration of $\mathrm{SnO}_{2}$ Nanoparticles with Micro-hotplatform for Low-power-consumption Gas Sensors
}

\author{
Shufeng Peng, ${ }^{1}$ Dongcheng Xie, ${ }^{2}$ Jin Wang, ${ }^{2}$ Minqiang Chen, ${ }^{2}$ and Lei $\mathrm{Xu}^{2 *}$ \\ ${ }^{1}$ School of Microelectronics, University of Science and Technology of China (USTC), Hefei 230027, China \\ ${ }^{2}$ School of Information Science and Technology, University of Science and Technology of China (USTC), \\ Hefei 230027, China
}

(Received May 25, 2018; accepted September 10, 2018)

Keywords: micro-hotplatform, $\mathrm{SnO}_{2}$ nanoparticles, MEMS, low power consumption

A gas sensor with low power consumption was manufactured using a suspended microhotplatform (MHP) fabricated by MEMS technology. Tin oxide nanoparticles, synthesized by the hydrothermal method, were deposited on the MHP by dip coating in the form of slurry. The obtained SEM images indicated that nanoparticles were well connected and uniform in size. The gas sensing performance was also investigated in both dynamic and static test systems. In the dynamic test system, the response $\left(R_{\text {air }} / R_{\text {gas }}\right)$ of the sensor exhibited a representative linear relationship with hydrogen at a power of $14.42 \mathrm{~mW}$ and changed from 1.17 to 4.51 at 5 to $100 \mathrm{ppm}$ hydrogen. In the static test system, the sensor demonstrated an obvious response to ethanol, ammonia, and glycol; the response to the target gas of ammonia at a concentration of $120 \mathrm{ppm}$ reached up to 23.94 . The power consumption of the sensor was only $16 \mathrm{~mW}$ with a platinum (Pt) heating resistor at $255^{\circ} \mathrm{C}$.

\section{Introduction}

Gas sensors have broad application prospects, for example, in civilian use, industry, and environmental monitoring. Nowadays, the dynamic market of intelligent homes ${ }^{(1)}$ and electronic noses ${ }^{(2)}$ provides tremendous opportunities for the application of gas sensors. The maturity of $\mathrm{MEMS}^{(3)}$ technology provides more possibilities for the development of sensors in the microscale direction, which can improve the performance of the sensors in terms of properties such as sensitivity, selectivity, and stability. Also, the power consumption and manufacturing cost can be greatly reduced.

Low power consumption is an important parameter in evaluating the properties of MEMS gas sensors. It has been widely reported that researchers can improve the performance of gas sensors by constantly optimizing the micro-hotplatform $(\mathrm{MHP})^{(4-14)}$ structure and the morphology of sensing materials. ${ }^{(15-19)}$ For example, in earlier research on MEMS gas sensors, Lee et al. ${ }^{(4)}$ described the great advantage of low power consumption compared with traditional gas sensors. Behera and Chandra reported that the heating resistor formed on a $\mathrm{SiO}_{2}$ platform of

*Corresponding author: e-mail: okxulei@ustc.edu.cn https://doi.org/10.18494/SAM.2018.2006 
$6 \mu \mathrm{m}$ thickness can save $43.5 \%$ of power through planar MEMS technology. ${ }^{(5)}$ The nickel etchback technique adopted by Bhattacharyya et al. ${ }^{(6)}$ decreased the power consumption to about $40 \mathrm{~mW}$ at $100{ }^{\circ} \mathrm{C}$. Furthermore, the closed-membrane-type design greatly reduced the power consumption, which was about 60 to $100 \mathrm{~mW}$ at $400{ }^{\circ} \mathrm{C}$, as was reported by Blaschke et al. ${ }^{(7)}$ and Baroncini et al. ${ }^{(8)}$ The suspended-membrane-type design had also been investigated widely: Lee et al. reported a low-power-consumption microscale $\mathrm{CO}_{2}$ gas sensor ${ }^{(9)}$ fabricated by $\mathrm{Si}$ dry etching, which showed a power consumption of $59 \mathrm{~mW}$. The suspended-membrane-type MHP was investigated by Rajeswara Rao et al. ${ }^{(11)}$ using molybdenum microheaters. The results indicated that the power consumption was $104 \mathrm{~mW}$ for a maximum temperature of $800{ }^{\circ} \mathrm{C}$. A double spiral hotplate MEMS gas sensor with the suspended-membrane structure was fabricated by wet etching using tetramethylammonium hydroxide (TMAH) solution, as demonstrated by Prasad and Khanna. ${ }^{(12)}$ The power consumption was about $20 \mathrm{~mW}$. Because of the heat flow in the MHP of a sensor, the suspended-membrane-type structure was conducive to the effective reduction in heat loss. In this study, a suspended-membrane-type gas sensor with $14.42 \mathrm{~mW}$ power consumption and supported by four supporting beams was fabricated.

Changing the morphology of the sensing materials is another effective way of improving the sensor performance. Kadir et al. ${ }^{(15)}$ presented well-aligned $\mathrm{SnO}_{2}$ nanofiber materials that could be operated at $150{ }^{\circ} \mathrm{C}$ for sensing hydrogen gas. The nanopore array was integrated with the MHP by Xu et al., ${ }^{(16)}$ leading to a strategy of in-site wafer-level fabrication of highperformance and low-power gas sensors. Tan et al. reported that an ultrathin nanosheet material mode realized by assembling hollow and hollowed-out $\mathrm{Co}_{3} \mathrm{O}_{4}$ microspheres exhibited a high response to ethanol. ${ }^{(18)}$ The sensing film was synthesized by hierarchically mixing $\mathrm{Pd} / \mathrm{SnO}_{2}$ (HM-PTO) composites, as reported by Xiao et al. ${ }^{(19)}$ However, the methods of synthesizing the above materials were somewhat complicated, and the growth process needed to be controlled precisely. The $\mathrm{SnO}_{2}$ nanoparticles were synthesized by a simple hydrothermal method in this study, compared with the above.

In this article, we present a feasible solution for fabricating semiconductor gas sensors through MEMS technology. $\mathrm{SnO}_{2}$ nanoparticles were deposited on the MHP by dip coating. The sensing film was characterized by SEM. The MHP with the suspended-membrane structure was fabricated by wet etching. The results of the investigation indicated that the sensor showed low power consumptions of $14.42 \mathrm{~mW}$ for sensing hydrogen gas and $16 \mathrm{~mW}$ for sensing ethanol, ammonia, and glycol gases.

\section{Experimental Methods}

\subsection{Structural design}

As shown in Fig. 1, the structure of the sensor chip consists of six layers from the bottom up: the silicon substrate, $\mathrm{SiO}_{2} / \mathrm{SiNx}$ supporting layer, Pt heating resistor, $\mathrm{SiNx}$ insulating layer, interdigital electrodes (IDEs), and sensing materials. The four supporting cantilevers are clearly seen in the schematic. They have a high mechanical strength and a low thermal stress. IDEs detect changes in the resistance of the $\mathrm{SnO}_{2}$ sensing film. Heat transfer mainly occurs by heat 


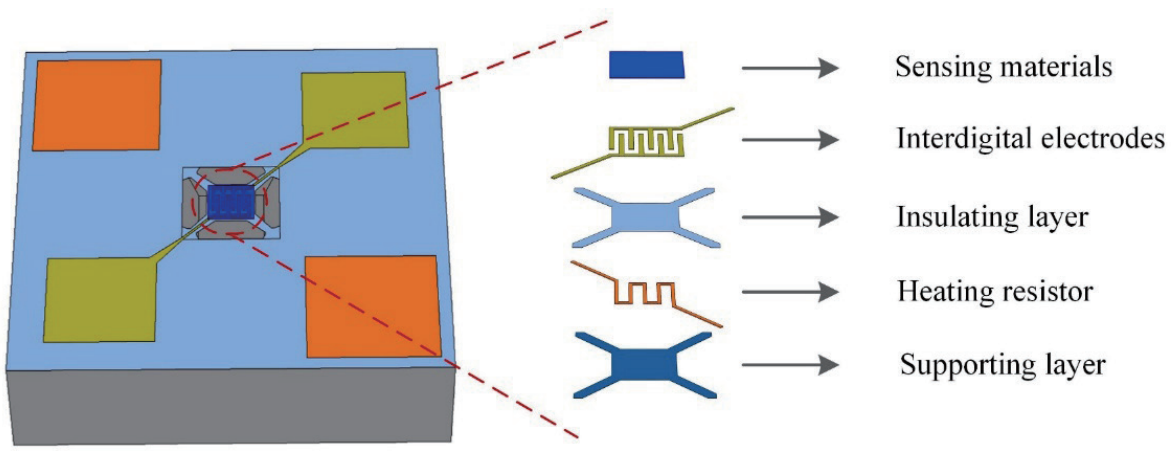

Fig. 1. (Color online) Diagram of the MEMS gas sensor chip structure with integrated heating resistor and IDEs.

conduction, convection, and radiation. The main heat losses in the substrate and membrane of the sensor occur due to heat conduction, heat convection, and radiation to the surrounding atmosphere. According to the law of energy conservation, the total heat transfer can be expressed as ${ }^{(10)}$

$$
\begin{aligned}
Q_{\text {total }}= & Q_{\text {conduction }}+Q_{\text {convection }}+Q_{\text {radiation }}+\Delta x \\
= & G_{\text {membrane }} \lambda_{\text {membrane }}\left(T_{\text {hot }}-T_{\text {ambient }}\right)+G_{\text {air }} \lambda_{\text {air }}\left(T_{\text {hot }}-T_{\text {ambient }}\right) \\
& +G_{\text {radiation }} \sigma \varepsilon\left(T_{\text {hot }}^{4}-T_{\text {ambient }}^{4}\right)+\Delta x,
\end{aligned}
$$

where $G_{\text {membrane, }} G_{\text {air }}$, and $G_{\text {radiation }}$ are geometry factors that mainly depend on the structure of the membrane. $T_{\text {hot }}$ and $T_{\text {ambient }}$ are the temperatures of the working area and ambient, and $\lambda_{\text {membrane }}$ and $\lambda_{\text {air }}$ are the thermal conductivities of the membrane and surrounding atmosphere, respectively. Moreover, $\varepsilon$ is the emissitivity and $\sigma$ is the Stefan-Boltzmann constant. $\Delta x$ shows other thermal losses including free convection. The suspended-membrane-type MHP suspended on a cavity through the support of four beams only. Therefore, heat can only be conducted through the suspended beams. In addition, the suspended-membrane structure reduces the geometric area where heat convection and radiation occur. Therefore, the utilization of heat generated by the heating resistor is greatly improved.

To evaluate the temperature distribution in the working area of the sensor chip, electrothermal simulation analysis was implemented using the simulation software COMSOL. The temperature distribution on the chip was obtained by simulating the voltage application of $1.5 \mathrm{~V}$ to the heating resistor, as shown in Fig. 2(a). It is obvious that the temperature of the working area is about $350{ }^{\circ} \mathrm{C}$, which is higher than that of the surrounding area, which is close to room temperature. Figure 2(b) shows the temperature distribution along the beam-working area-beam. It also shows that the thermal distribution of the working area is higher and uniform, and that the average temperature gradient is about $0.32{ }^{\circ} \mathrm{C} / \mu \mathrm{m}$. The temperature along the supporting beams decreases quickly until it equals the Si substrate temperature when the location is far from the working area, indicating that much of the heat loss of the MHP was through the supporting beams to the substrate by heat conduction. Because the sensitive 


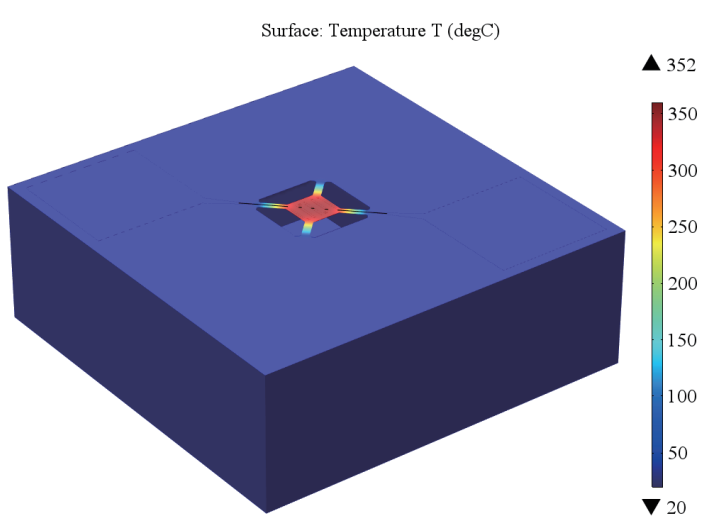

(a)

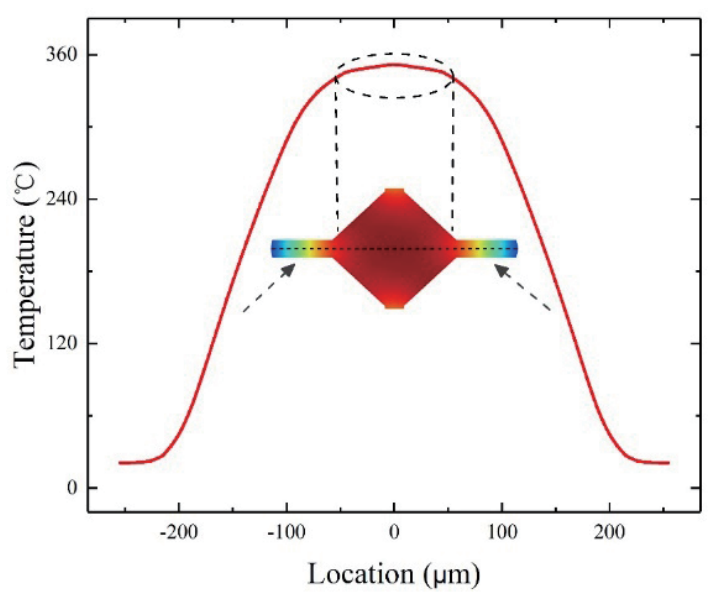

(b)

Fig. 2. (Color online) Electrothermal simulation analysis. (a) Temperature distribution on the sensor chip. (b) Temperature distribution along beam-working area-beam.

properties of $\mathrm{SnO}_{2}$ nanomaterials are related to the operating temperature, the nonuniform temperature distribution in the central working area may result in a cross response. From the simulation results, a homogeneous-temperature field can be obtained, which would enable the sensing materials to avoid the cross response effectively. However, the above simulation experiments are based on ideal boundary conditions and the results are slightly different from the actual data.

\subsection{MHP fabrication}

MEMS fabrication, which was adopted for the gas sensor, mainly includes thermal oxidation, lithography, chemical vapor deposition, sputtering, etching, bonding, and packaging. The complete sensor manufacturing processes are shown in Fig. 3, and detailed procedures are described below.

(i) $\mathrm{A} \mathrm{SiO}_{2}$ layer with a thickness of $300 \mathrm{~nm}$ was generated on an N-type $<100>$-oriented silicon wafer by thermal oxidation.

(ii) A SiNx film with a thickness of $300 \mathrm{~nm}$ was deposited on the $\mathrm{SiO}_{2}$ layer by low-pressure chemical vapor deposition (LPCVD). $\mathrm{SiO}_{2} / \mathrm{SiNx}$ films mainly serve as supporting layers for the suspended membrane structure.

(iii) The shape of the heating resistor was etched by UV lithography. Then, Pt $(200 \mathrm{~nm}$ thick) was sputtered and the heating resistor was finally formed by the lift-off process in acetone solution, which determined the operating temperature for nanomaterials.

(iv) Another SiNx insulating layer with a thickness of $300 \mathrm{~nm}$ was deposited on the heater layer by plasma-enhanced chemical vapor deposition (PECVD).

(v) The heating pads were exposed by reactive-ion etching (RIE). 
( i )

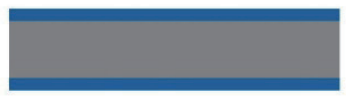

(iv)

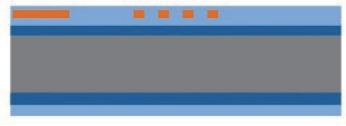

(vii)

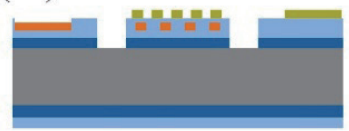

(ii)

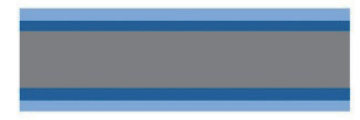

( v )

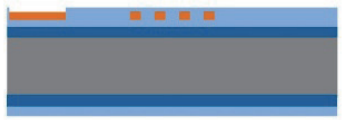

(viii)

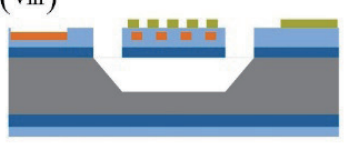

(iii)

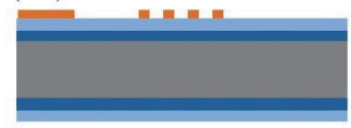

(vi)
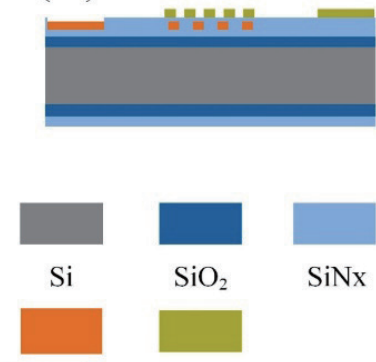

Pt Resistor Pt IDEs

Fig. 3. (Color online) Fabrication process of the MHP.

(vi) The Pt IDEs (200 nm thick) were fabricated by the same procedure as in (iii).

(vii) The front corrosion windows were opened by the RIE of the $\mathrm{SiO}_{2} / \mathrm{SiNx}$ membrane because of the high selectivity to the photoresist, and the silicon substrate was ultimately exposed.

(viii) The suspended MHP was released by wet anisotropic etching adopting an etching solution of TMAH.

Finally, the sensor properties were investigated after dicing, wire bonding, and packaging.

\subsection{Sensing material synthesis}

Tin oxide, an extensively investigated wide-band-gap semiconductor sensing material, was adopted in this study. The hydrothermal method ${ }^{(20)}$ was used to synthesize $\mathrm{SnO}_{2}$ from a precursor solution of $\mathrm{SnCl}_{4}$, as expressed by the chemical equation

$$
\mathrm{Sn}^{4+}+4 \mathrm{OH}^{-} \rightarrow \mathrm{SnO}_{2}+2 \mathrm{H}_{2} \mathrm{O}
$$

First, the prepared $\mathrm{SnCl}_{4} \cdot 5 \mathrm{H}_{2} \mathrm{O}$ was dissolved in a beaker with moderate deionized water. Then, $\mathrm{NaOH}$, which instantly reacts with $\mathrm{SnCl}_{4}$, was added with milling. ${ }^{(21)}$ After continuous stirring for $30 \mathrm{~min}$, the solution was transferred into a stainless-steel reactor with a capacity of $100 \mathrm{ml}$. After sealing the reactor, it was placed into a constant-temperature oven at $180{ }^{\circ} \mathrm{C}$ for $12 \mathrm{~h}$. The product was collected after it was cooled naturally to room temperature, centrifuged, and washed several times with deionized water and ethanol. Finally, the achieved samples were placed into the holding furnace and dried at $80{ }^{\circ} \mathrm{C}$ for $6 \mathrm{~h}$ to obtain $\mathrm{SnO}_{2}$ powder samples. This method of synthesizing sensing materials was simple, easily repeatable, and easy to acquire in batches. 


\subsection{Sensing mechanism}

The influence of metal oxide semiconductor nanomaterials on the performance of sensors was investigated by analyzing the sensing mechanism of metal oxide. The basic principle of the sensing mechanism originates from the change in the electrical conductivity of the metal oxide sensing film, owing to the reaction kinetics among the adsorbed oxygen species and target gas molecules on the surface of materials. ${ }^{(22)}$ As shown in Fig. 4, the oxygen molecules adsorbed on the face of materials transform into various oxygen species, including $\mathrm{O}_{2}{ }^{-}, \mathrm{O}^{2-}$, and $\mathrm{O}^{-}$, by capturing free electrons from the conduction band $(E c)$ of the metal oxide, ${ }^{(23)}$ which is expressed as

$$
\mathrm{O}_{2}+\mathrm{e}^{-} \rightarrow \mathrm{O}_{2}^{-}, \mathrm{O}^{-} \text {, or } \mathrm{O}^{2-} \text {. }
$$

As a result, a space charge layer is formed, which causes the carrier concentration and electron mobility to decline. However, when the gas sensor is exposed to a reducing gas, such as hydrogen, redox reactions [Eqs. (4)-(6)] $]^{(24-26)}$ with the oxygen species adsorbed on the surface occur, leading to a decrease in the concentration of surface ionic oxygen species, and the trapped electrons are released into the conduction band and contribute to the decrease in the resistance of the nanomaterials. $e V_{o}$ and $e V_{R}$ are respectively the potential barrier voltages at the $\mathrm{SnO}_{2}$ interface in air and target gas.

$$
\begin{gathered}
\mathrm{H}_{2}+\mathrm{O}^{-} \rightarrow \mathrm{H}_{2} \mathrm{O}+\mathrm{e}^{-}, \\
\mathrm{H}_{2}+\mathrm{O}^{2-} \rightarrow \mathrm{H}_{2} \mathrm{O}+2 \mathrm{e}^{-}, \\
2 \mathrm{H}_{2}+\mathrm{O}_{2}^{-} \rightarrow 2 \mathrm{H}_{2} \mathrm{O}+\mathrm{e}^{-} .
\end{gathered}
$$

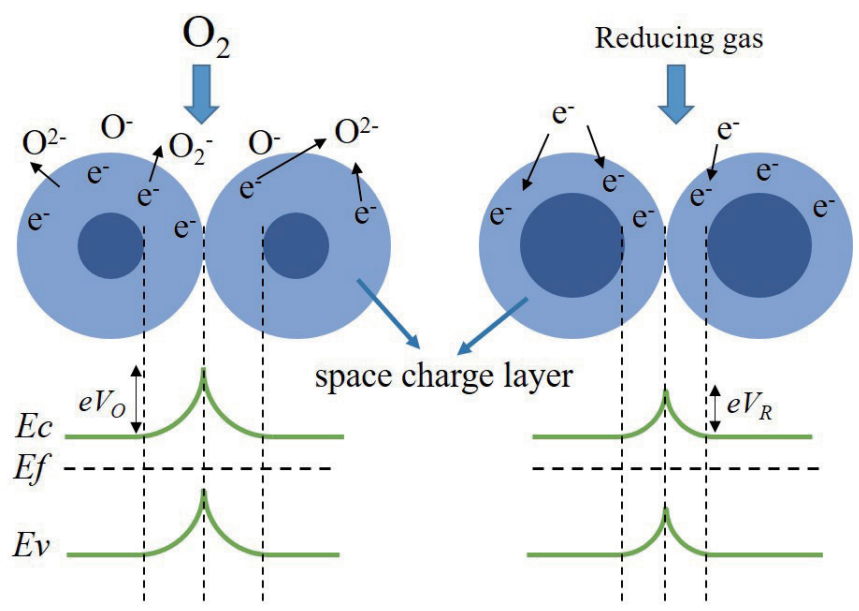

Fig. 4. (Color online) Schematic of the change in interface barrier of $\mathrm{SnO}_{2}$ grains. 


\subsection{Sensor measurements}

The gas response characteristics of the proposed sensor were investigated with a seriesconnected allotting circuit using our original experimental equipment, as shown in Fig. 5. Figure 5(a) shows the measuring circuit. ${ }^{(27)}$ The optimal operating temperature for sensingfilm resistance $\left(R_{S}\right)$ can be obtained by changing the heating voltage $\left(V_{H}\right)$ applied to the heating resistance $\left(R_{H}\right)$. The output voltage $\left(V_{O U T}\right)$, which indicates the response of the sensor, is sampled under different conditions of load resistance $\left(R_{L}\right)$ and transmitted to a host computer for recording and subsequent analysis. Figures 5(b) and 5(c) show the static and dynamic test systems, respectively. In the static test system, the target gas is injected into an airtight chamber and diluted with air to obtain the predetermined concentration of gas. In the dynamic test system, standard target gas and dry air are connected to the input of mass flow controllers (MFCs), in which the valve opening ( 0 to $100 \%)$ and flow rate $(500 \mathrm{sccm})$ are controlled by a computer. The output of MFCs is connected to a two-input gas mixer to obtain the predetermined

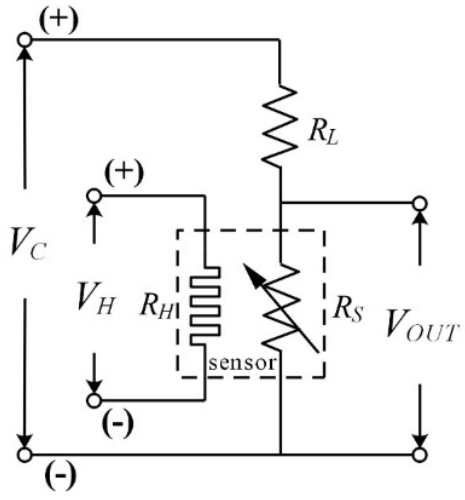

(a)

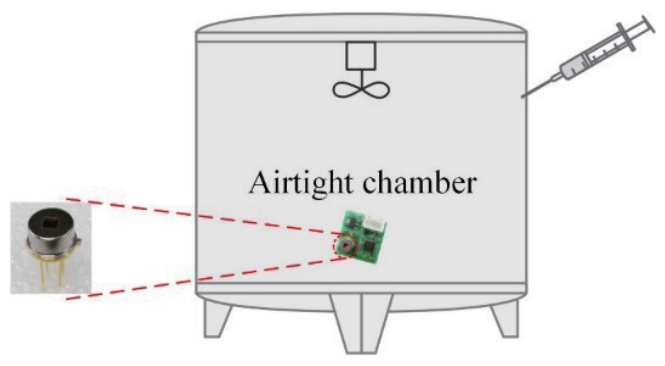

(b)

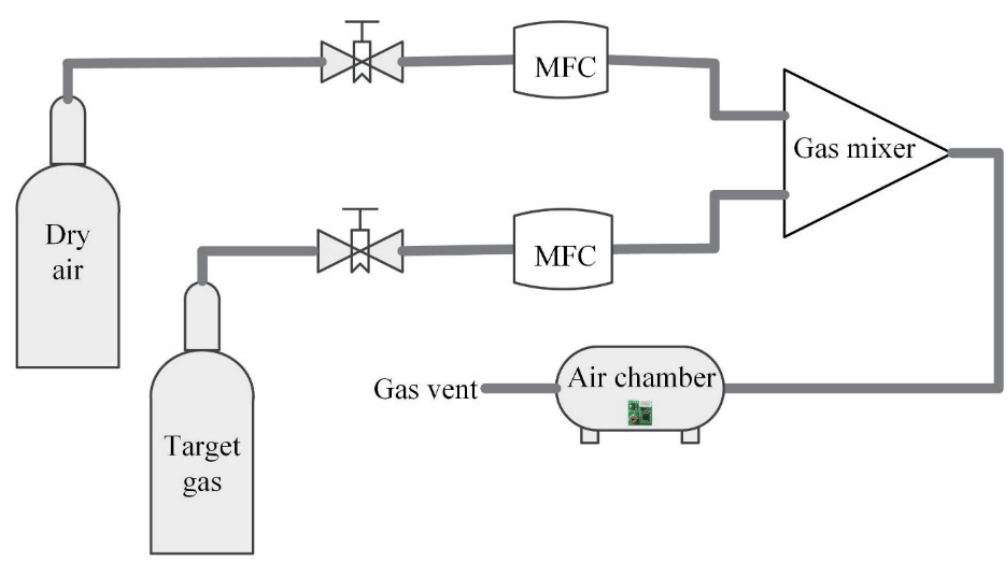

(c)

Fig. 5. (Color online) Schematic of measuring circuit and our original experimental equipment. (a) Measuring circuit. (b) Static test system. (c) Dynamic test system. 
concentration of gas. For example, if the $20 \mathrm{ppm}$ concentration of hydrogen is needed, the valve opening of MFC that is connected to the standard 100 ppm hydrogen gas is set at $20 \%$, and the valve opening of MFC that is connected to the dry air is set at $80 \%$. The gas sensor is placed in a test chamber of about $100 \mathrm{~mL}$ (dynamic mode) and $19 \mathrm{~L}$ (static mode) volume. The ambient temperature and humidity are $20{ }^{\circ} \mathrm{C}$ and $60 \%$ (static mode), respectively.

\section{Results and Discussion}

\subsection{Morphological characterizations}

The $\mathrm{SnO}_{2}$ nanomaterial film was characterized and analyzed after deposition on IDEs and annealing. Figure 6 shows the structure of the MHP and the morphology of the $\mathrm{SnO}_{2}$ sensing film observed by SEM under different magnifications. In Fig. 6(a), the MHP with the suspended-membrane structure, which was fabricated with an area of $150 \times 150 \mu \mathrm{m}^{2}$, is clearly presented. It can be seen that the $\mathrm{SnO}_{2}$ nanoparticles are uniformly distributed over the active area and well integrated with the MHP. Figure 6(b) reveals that $\mathrm{SnO}_{2}$ nanoparticles are in good contact with each other and the average nanoparticle diameter is about $25 \mathrm{~nm}$. The morphology and space distribution of the $\mathrm{SnO}_{2}$ film structure can increase the contact rate with gas molecules, which greatly enhances the sensitivity of the sensor. The film structure of the sensing nanomaterials is heated easily and has a uniform heat distribution, and the extremely small nanoparticles increase the activity of the nanomaterials. Improvements of the materials enable the gas sensor to exhibit good sensitive properties at about $250{ }^{\circ} \mathrm{C}$. The operating temperature is reduced by 25 to $40 \%$ when compared with that for traditional $\mathrm{SnO}_{2}$ at an operating temperature of about $400{ }^{\circ} \mathrm{C}$.

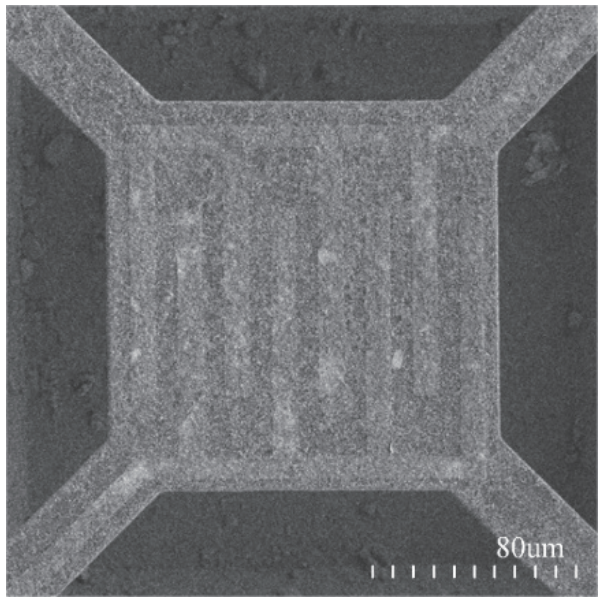

(a)

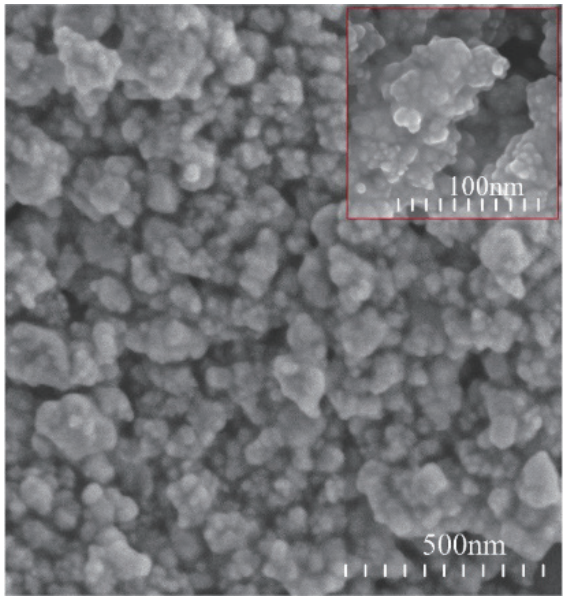

(b)

Fig. 6. (Color online) SEM images of (a) structure of MHP and (b) morphology of $\mathrm{SnO}_{2}$ sensing film. 


\subsection{Temperature versus power}

The operating temperature of the heating resistor was investigated using ${ }^{(28)}$

$$
T=\frac{R-R_{0}}{\alpha \times R_{0}}+T_{0}
$$

where $R_{0}$ is the initial resistance at the room temperature $T_{0}, R$ is the resistance at the temperature $T$, and $\alpha$ is the temperature coefficient of the resistance of the Pt heater. ${ }^{(29)}$ However, it is a simplified equation; the temperature calculated using Eq. (7) is slightly lower than the actual temperature. ${ }^{(30)}$ Thus, the curve seen in Fig. 7 presents nonlinearity. The heating voltage was applied from a voltage source and the current through the heating resistor was measured. Then, the dependence of the heating resistor temperature on the loaded power was calculated using Eq. (7) and is shown in Fig. 7. Thus, the operating temperature of the $\mathrm{SnO}_{2}$ sensing membrane can be easily obtained by changing the heating power consumption. From Fig. 7, we know that the temperature exceeds $200{ }^{\circ} \mathrm{C}$ when more than $11 \mathrm{~mW}$ power is loaded and reaches $400{ }^{\circ} \mathrm{C}$ at about $32 \mathrm{~mW}$. The suspended-membrane structure reduces the power consumption by 50 to $70 \%$ compared with the closed-membrane-type ones at the operating temperature of about $400{ }^{\circ} \mathrm{C}$.

As expressed in Eq. (1), thermal losses through heat conduction and convection are linear with temperature. However, the thermal loss through radiation is proportional to temperature to the fourth power $\left(T^{4}\right)$. Puigcorbe et al. ${ }^{(31)}$ reported that thermal loss through radiation is a negligible fraction if the temperature of the MHP is lower than $400{ }^{\circ} \mathrm{C}$. At a higher operation temperature, however, heat radiation is an essential way of heat loss, which is also an important factor for the nonlinear curve of temperature versus power.

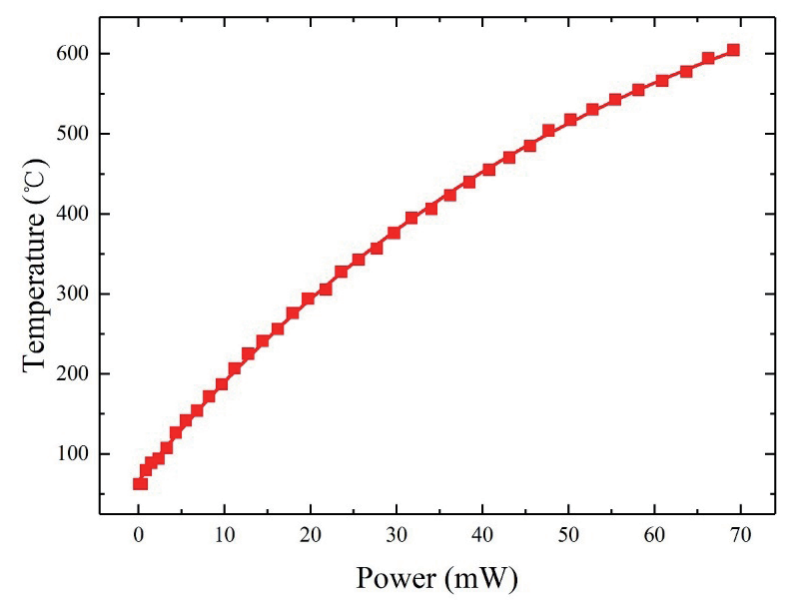

Fig. 7. (Color online) Temperature versus power of the heating resistor. 


\subsection{Sensor properties}

The gas sensing performance of the sensor was investigated by measuring the change in the electrical conductivity of the sensing film at various concentrations of the target gas. Response $(S)$ is a significant parameter for assessing the sensor performance. In this article, it is defined as

$$
S=\frac{R_{\text {air }}}{R_{\text {gas }}}
$$

where $R_{\text {air }}$ is the initial resistance of the sensing film in air and $R_{\text {gas }}$ is the steady resistance obtained after exposure to the target gas. In accordance with the circuit diagram in Fig. 5(a), the resistance $R_{S}$ is calculated as

$$
R_{S}=\frac{V_{\text {OUT }} \times R_{L}}{V_{C}-V_{\text {OUT }}}
$$

where $R_{S}$ is $R_{\text {air }}$ or $R_{\text {gas }}$ depending on the gas atmosphere in which the sensor is placed.

The sensing properties for hydrogen gas were investigated using our original experimental equipment in the dynamic mode. The response and recovery curves of the sensor are shown in Fig. 8. The proposed gas sensor was exposed to 5 to $100 \mathrm{ppm}$ hydrogen by controlling the MFC flow. Here, an investigation using different heating voltages $\left(V_{H}=1.3,1.4,1.5\right.$, and $\left.1.6 \mathrm{~V}\right)$ was carried out to explain the effect of temperature on the sensing materials. It can be seen that the output voltage drops to a stable value when exposed to hydrogen and returns to its initial value when switched to dry air. The response amplitude increases with the increase in hydrogen concentration. In Fig. 8(a), a better linear relationship of the response is presented in the inset. The R-squared values of the linear fitting to the heating voltages $V_{H}$ of $1.3,1.4,1.5$, and $1.6 \mathrm{~V}$ are $0.99951,0.99932,0.99804$, and 0.99622 , respectively. The R-squared parameter represents the degree of correlation of the fitted curve. The closer its value to 1, the better the correlation. However, the intercept and slope, which characterize the increase rate of the response, are both lower than those in the other three cases. The sensor should take more time to reach a stable state in the target gas and dry air owing to the low operating temperature supplied with a heating voltage of $1.3 \mathrm{~V}$. Also, a distinct upward drift of the baseline of the initial voltage in dry air occurred. The plots of response in Figs. 8(b)-8(d) all demonstrate a representative linear relationship with similar intercepts and slopes among them. For further study, $S_{p}$ is adopted as

$$
S_{p}=\frac{S}{P}
$$

where $P$ is the power of the heating resistor and $S_{p}$ is the ratio of response $(S)$ to power $(P)$. The greater $S_{p}$ is, the higher the response and the lower the power consumption of the sensor. Thus, as seen in Fig. 9, when $V_{H}=1.4 \mathrm{~V}$ was applied to the heating resistor and the sensor was 


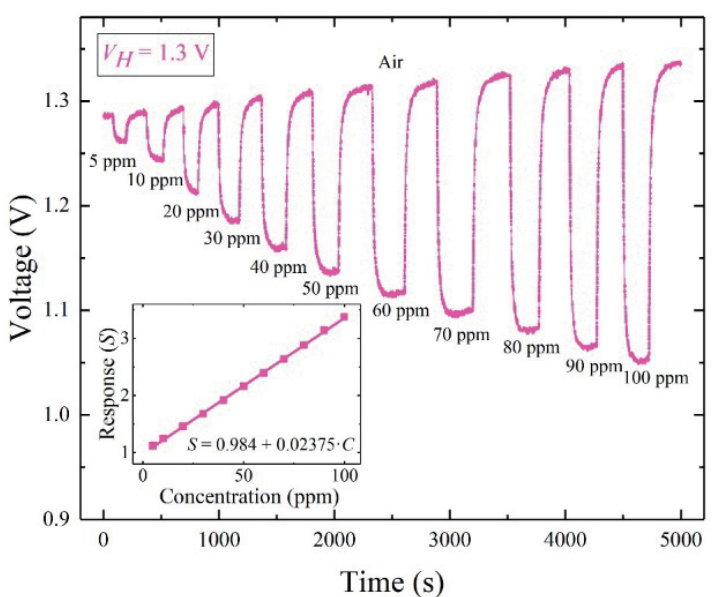

(a)

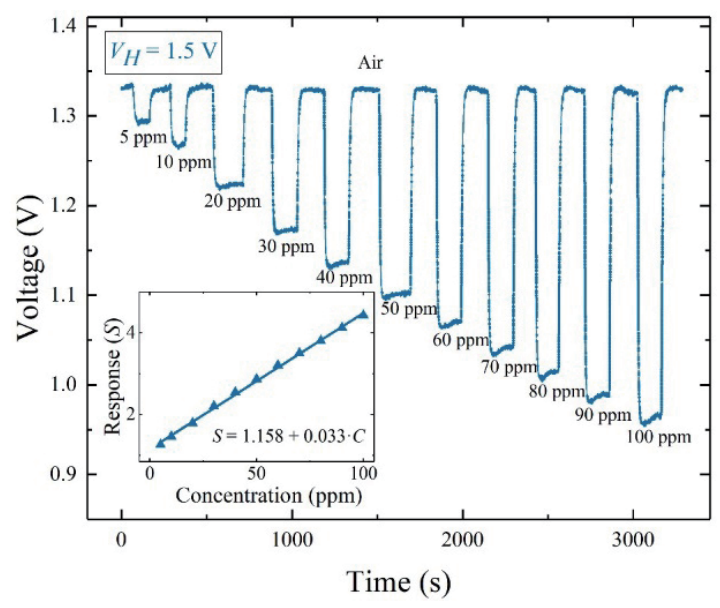

(c)

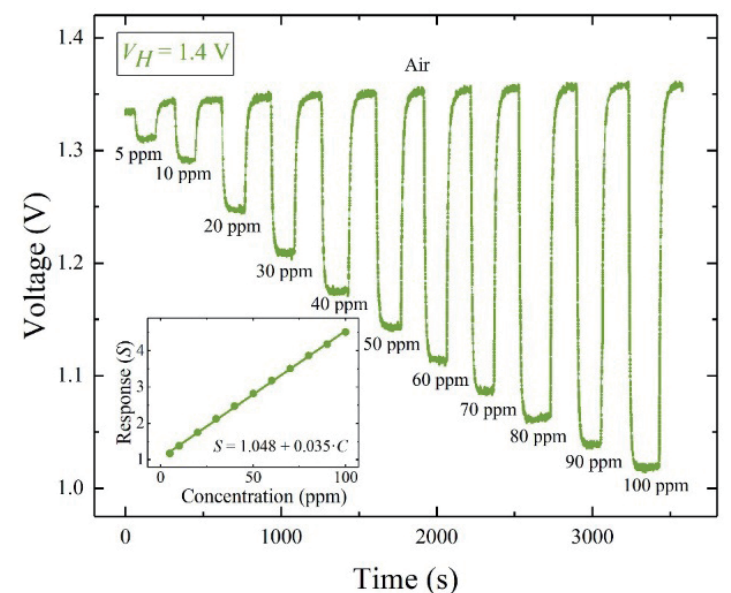

(b)

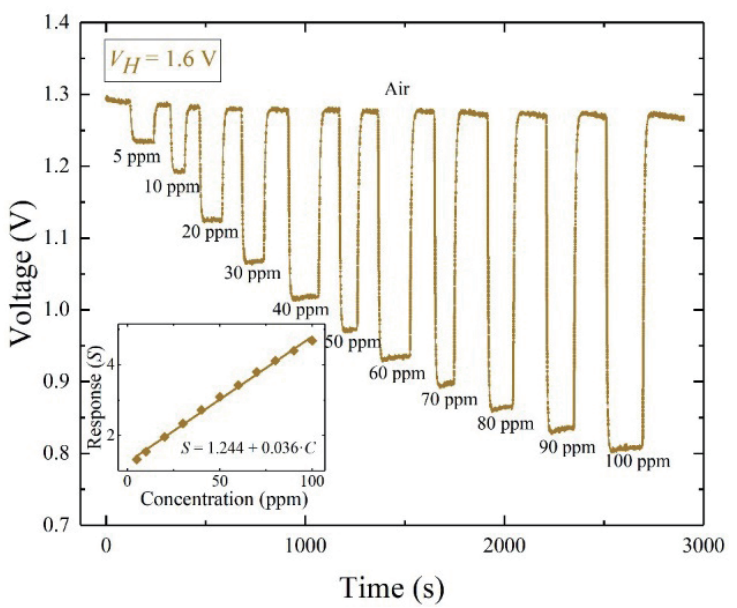

(d)

Fig. 8. (Color online) Response and recovery curves of sensor to different hydrogen concentrations (5 to $100 \mathrm{ppm}$ ). (a) $V_{H}=1.3 \mathrm{~V}$. (b) $V_{H}=1.4 \mathrm{~V}$. (c) $V_{H}=1.5 \mathrm{~V}$. (d) $V_{H}=1.6 \mathrm{~V}$.

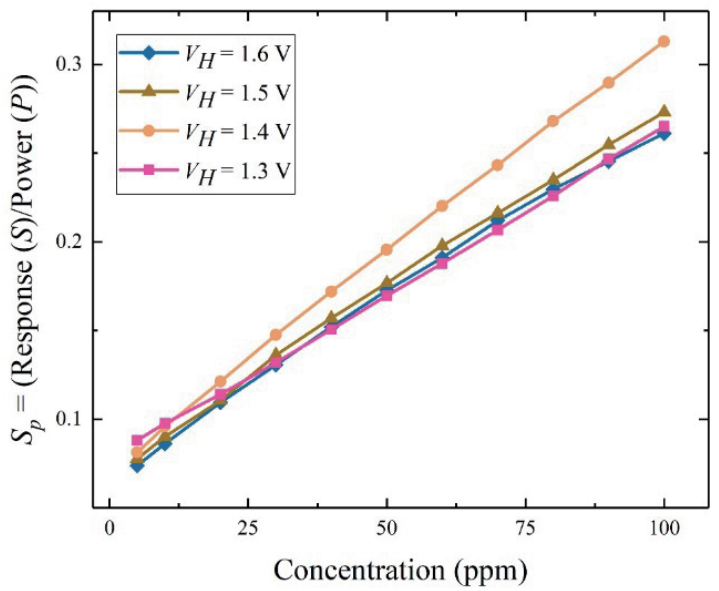

Fig. 9. (Color online) Diagram of response/power versus hydrogen concentration. 
exposed to more than $10 \mathrm{ppm}$ hydrogen, a high response and a low power consumption are obtained. According to Fig. 7, the power consumption is only $14.42 \mathrm{~mW}$, which is superior to those of traditional sensors, such as Figaro TGS2600 $(210 \mathrm{~mW}),{ }^{(32)}$ and slightly lower than those of similar MEMS gas sensors reported previously. The temperature of the heating resistor is about $240{ }^{\circ} \mathrm{C}$.

Glycol, ammonia, and ethanol were also characterized using the static test system. The target gas was injected into an airtight chamber and diluted with air to a predetermined concentration of test gas. The heating voltage $V_{H}$ of $1.5 \mathrm{~V}$ was applied, which is comparable to that in our previous report. ${ }^{(33)}$ Figure 10 shows a curve of typical responses to glycol, ammonia, and ethanol at different concentrations. It can be seen that the responses are greatly improved when compared with those of the previous sensor. The power is about $16 \mathrm{~mW}$. The responses are distinct, that is, the response to ammonia is higher than those to ethanol and glycol at

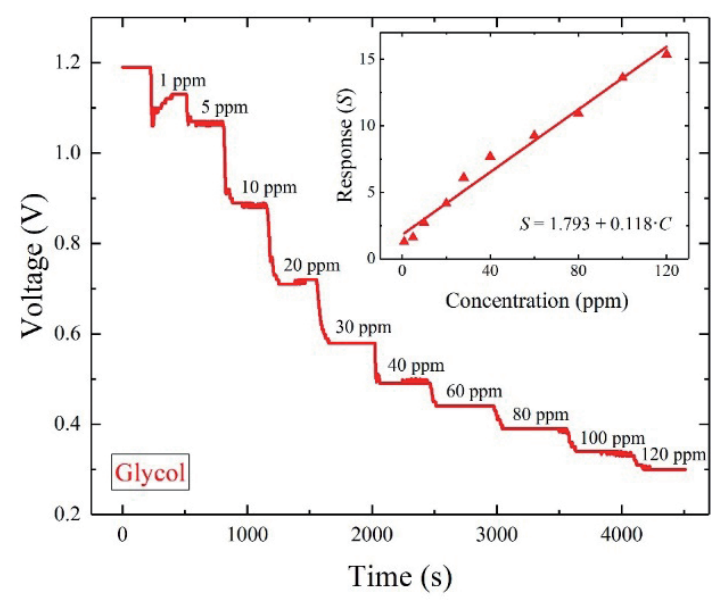

(a)

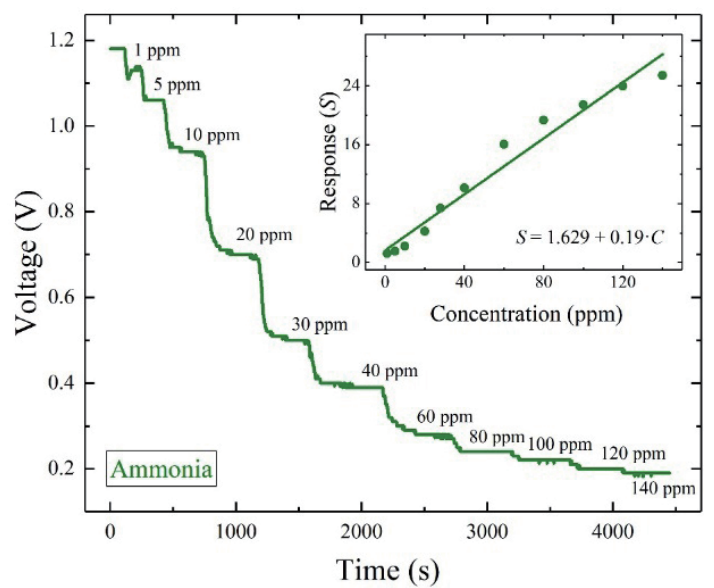

(b)

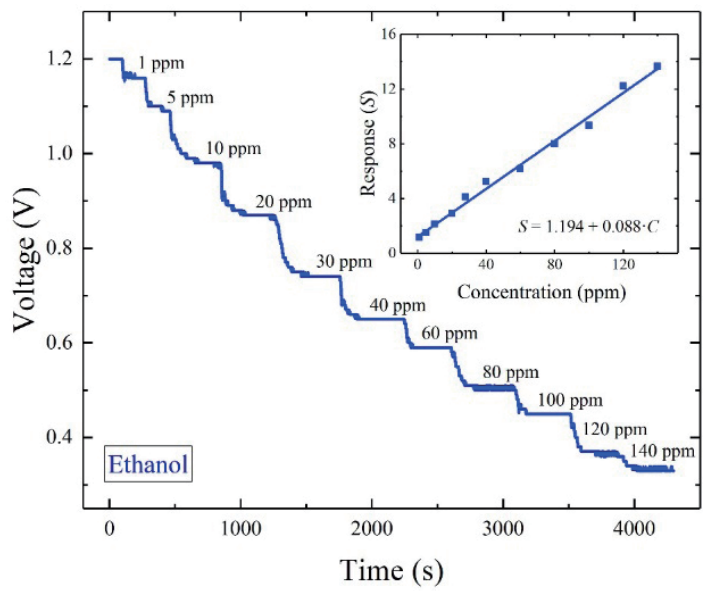

(c)

Fig. 10. (Color online) Response curves of sensor at different concentrations of (a) glycol, (b) ammonia, and (c) ethanol. 
concentrations above $10 \mathrm{ppm}$ and increases rapidly with increasing concentration. However, the linear relationship between the ammonia concentration and the response is poor in the range from 1 to $120 \mathrm{ppm}$ compared with those for ethanol and glycol. The R-squared values of the linear fitting to glycol, ammonia, and ethanol are 0.9796, 0.9625, and 0.9910, respectively. From the diagram, the response is seen to reach 12.22, 15.36, and 23.94 for glycol, ammonia, and ethanol at $120 \mathrm{ppm}$, respectively. It can be concluded that the adsorption capacity of the sensing film for different target gases is different, as is the change in response.

\section{Conclusions}

Semiconductor gas sensors with low power consumption were successfully fabricated using the MHP with a $\mathrm{SnO}_{2}$ sensing film. Morphological characterizations of the $\mathrm{SnO}_{2}$ sensing film by SEM demonstrated that the nanoparticles were well connected and the diameter was homogeneous (about $25 \mathrm{~nm}$ ). The sensor with the suspended-membrane structure presented a representative linear relationship to hydrogen at 5 to $100 \mathrm{ppm}$. The power consumption was only $14.42 \mathrm{~mW}$ with the Pt heating resistor at $240{ }^{\circ} \mathrm{C}$, while the response-to-power ratio became the largest. The sensor demonstrated obvious responses to ethanol, ammonia, and glycol in the static mode. The response reached 23.94 for ammonia at $120 \mathrm{ppm}$. The power consumption of the sensor was only $16 \mathrm{~mW}$ with the Pt heating resistor heater at $255^{\circ} \mathrm{C}$.

\section{Acknowledgments}

The authors would like to acknowledge the support of the Micro/Nano-Electronic System Integration Center (MESIC) in USTC. This work was partially carried out at the USTC Center for Micro and Nanoscale Research and Fabrication.

\section{References}

1 S. L. Dong, S. H. Duan, Q. Yang, J. L. Zhang, G. G. Li, and R. Y. Tao: IEEE IoT J. 4 (2017) 1296. https://doi. org/10.1109/JIOT.2017.2676678

2 A. Loutfi, S. Coradeschi, G. K. Mani, P. Shankar, and J. B. B. Rayappan: J. Food Eng. 144 (2015) 103. https:// doi.org/10.1016/j.jfoodeng.2014.07.019

3 W. H. Ko: Sens. Actuators, A 136 (2007) 62. https://doi.org/10.1016/j.sna.2007.02.001

4 D.-D. Lee, W.-Y. Chung, M.-S. Choi, and J.-M. Baek: Sens. Actuators, B 33 (1996) 147. https://doi. org/10.1016/0925-4005(96)01822-9

5 B. Behera and S. Chandra: Sens. Actuators, B 229 (2016) 414. https://doi.org/10.1016/j.snb.2016.01.079

6 P. Bhattacharyya, P. K. Basu, B. Mondal, and H. Saha: Microelectron. Reliab. 48 (2008) 1772. https://doi. org/10.1016/j.microrel.2008.07.063

7 M. Blaschke, T. Tille, P. Robertson, S. Mair, U. Weimar, and H. Ulmer: IEEE Sens. J. 6 (2006) 1298. https:// doi.org/10.1109/JSEN.2006.881399

8 M. Baroncini, P. Placidi, G. C. Cardinali, and A. Scorzoni: Sens. Actuators, A 115 (2004) 8. https://doi. org/10.1016/j.sna.2004.03.012

9 J. Lee, N. J. Choi, H. K. Lee, J. Kim, S. Y. Lim, J. Y. Kwon, S. M. Lee, S. E. Moon, J. J. Jong, and D. J. Yoo: Sens. Actuators, B 248 (2017) 957. https://doi.org/10.1016/j.snb.2017.02.040

10 P. Bhattacharyya: IEEE Trans. Device Mater. Reliab. 14 (2014) 589. https://doi.org/10.1109/ TDMR.2014.2311801

11 L. L. Rajeswara Rao, M. K. Singha, K. M. Subramaniam, N. Jampana, and S. Asokan: IEEE Sens. J. 17 (2017) 22. https://doi.org/10.1109/JSEN.2016.2621179 
12 M. Prasad and V. K. Khanna: Microsyst. Technol. 21 (2015) 2123. https://doi.org/10.1007/s00542-014-2393-3

13 R. Prajesh, N. Jain, and A. Agarwal: Microsyst. Technol. 22 (2015) 2185. https://doi.org/10.1007/s00542-0152609-1

14 S. L. Marasso, A. Tommasi, D. Perrone, M. Cocuzza, R. Mosca, M. Villani, A. Zappettini, and D. Calestani: Nanotechnology 27 (2016) 385503. https://doi.10.1088/0957-4484/27/38/385503

15 R. Ab Kadir, Z. Li, A. Z. Sadek, R. Abdul Rani, A. S. Zoolfakar, M. R. Field, J. Z. Ou, A. F. Chrimes, and K. Kalantar-zadeh: J. Phys. Chem. C 118 (2014) 3129. https://doi.org/10.1021/jp411552z

16 L. Xu, Z. Dai, G. Duan, L. Guo, Y. Wang, H. Zhou, Y. Liu, W. Cai, Y. Wang, and T. Li: Sci. Rep. 5 (2015). https://doi.org/10.1038/srep10507

17 L. F. Zhu, J. C. She, J. Y. Luo, S. Z. Deng, J. Chen, X. W. Ji, and N. S. Xu: Sens. Actuators, B 153 (2011) 354. https://doi.org/10.1016/j.snb.2010.10.047

18 J. Tan, M. Dun, L. Li, J. Zhao, W. Tan, Z. Lin, and X. Huang: Sens. Actuators, B 249 (2017) 44. https://doi. org/10.1016/j.snb.2017.04.063

19 L. Xiao, S. Xu, G. Yu, and S. Liu: Sens. Actuators, B 255 (2018) 2002. https://doi.org/10.1016/j.snb.2017.08.216

20 G. E. Patil, D. D. Kajale, V. B. Gaikwad, and G. H. Jain: Int. Nano Lett. 2 (2012) 17. https://doi. org/10.1186/2228-5326-2-17

21 S. Wang, J. Yang, H. Zhang, Y. Wang, X. Gao, L. Wang, and Z. Zhu: Sens. Actuators, B 207 (2015) 83. https:// doi.org/10.1016/j.snb.2014.10.032

22 P. Tyagi, A. Sharma, M. Tomar, and V. Gupta: Sens. Actuators, B 224 (2016) 282. https://doi.org/10.1016/ j.snb.2015.10.050

23 C. Wang, L. Yin, L. Zhang, D. Xiang, and R. Gao: Sensors 10 (2010) 2088. https://doi.org/10.3390/s100302088

24 O. Lupan, G. Chai, and L. Chow: Microelectron. Eng. 85 (2008) 2220. https://doi.org/10.1016/j.mee.2008.06.021

25 G. Lu, N. Miura, and N. Yamazoe: Sens. Actuators, B 35 (1996) 130. https://doi.org/10.1016/S09254005(97)80042-1

26 N. Yamazoe and K. Shimanoe: Sens. Actuators, B 138 (2009) 100. https://doi.org/10.1016/j.snb.2009.01.023

27 L. Gao, Z. Cheng, Q. Xiang, Y. Zhang, and J. Xu: Sens. Actuators, B 208 (2015) 436. https://doi.org/10.1016/ j.snb.2014.11.053

28 L. Xu, Y. Wang, H. Zhou, Y. Liu, T. Li, and Y. Wang: J. Microelectromech. Syst. 21 (2012) 1402. https://doi. org/10.1109/JMEMS.2012.2208219

29 H. Jiang, M. Huang, Y. Yu, X. Tian, X. Zhao, W. Zhang, J. Zhang, Y. Huang, and K. Yu: Sensors 18 (2017) 94. https://doi.org/10.3390/s18010094

30 M. V. Dusen: J. Am. Chem. Soc. 47 (1925) 326. https://doi.org/10.1021/ja01679a007

31 J. Puigcorbe, D. Vogel, B. Michel, A. Vila, I. Gracia, C. Cane, and J. Morante: J. Micromech. Microeng. 13 (2003) 548. https://doi.org/10.1088/0960-1317/13/5/304

32 Figaro: http://www.figaro.co.jp/en/ (accessed May 2018).

33 J. Wang, J. Yang, D. Chen, L. Jin, Y. Li, Y. Zhang, L. Xu, Y. Guo, F. Lin, and F. Wu: IEEE Sens. J. 18 (2018) 6765. https://doi.org/10.1109/JSEN.2018.2829742 